九州大学学術情報リポジトリ

Kyushu University Institutional Repository

Dynamic of Water Transport in Napiergras (Pennisetum purpureum Schumach) Plant : Relationship between Water Transport Regulation and Water Storage Capacity in the Diurnal Water Balance

Nagasuga, Kiyoshi

National Institute of Agrobiological Sciencies

https://doi.org/10.5109/4586

出版情報: 九州大学大学院農学研究院紀要. 49 (2)，pp.263-271，2004-10-01. Faculty of Agriculture, Kyushu University

バージョン：

権利関係 : 


\title{
Dynamic of Water Transport in Napiergrass (Pennisetum purpureum Schumach) Plant - Relationship between Water Transport Regulation and Water Storage Capacity in the Diurnal Water Balance -
}

\author{
Kiyoshi NAGASUGA ${ }^{1 *}$ \\ Institute of Tropical Agriculture, Kyushu University, Fukuoka 812-8581, Japan \\ (Received June 30, 2004 and accepted July 13, 2004)
}

\begin{abstract}
The characteristics of economical water transport in napiergrass were investigated with respect to water transport regulation by the nodal stem and a water storage capacity (WSC), partly compensation for transpiration with water in the plant. Changes in leaf photosynthesis after plant excisions suggested that water transport to the leaves was mainly regulated by the nodal stem in the morning and the stem base regulated instead in the afternoon. Contrary to Plant transpiration rate $(P T r)$, water absorption rate by roots $(S F)$ increased slowly and leaf water potential ( $\left.\Psi_{\text {leat }}\right)$ decreased in the morning. However, because of $S F$ increase, $\Psi_{\text {lear }}$ gradually recovered in the afternoon. It was considered that water conditions would be related to the change in regulating position. Gap of diurnal changes in two parameters suggested WSC could contribute to maintenance of $P T r$, and it was estimated that $W S C$ compensated $8 \%$ of total PTr. On the other hand, WSC of pot-cultivated plant was estimated to be $3 \%$ and WSC in stem was higher than that of leaf from the relationship between $P T r$ and decrease in water content of plant parts. It was considered that these were involved in controlling water balance in napiergrass.
\end{abstract}

\section{INTRODUCTION}

Water is absorbed by the roots, moves through the plant organs and largely evaporates from the leaf surface to the atmosphere in a plant. The main driving force of this water movement is the demand for transpiration in the atmosphere. This parameter usually becomes stronger and causes most plants to show mild water stress in the afternoon (Ishihara et al., 1981), so it is important for the realization of vigorous plant growth to maintain well water conditions during the daytime and under drought conditions.

Napiergrass is known as the species with the highest productivity and an outstanding adaptability to various kind of environmental conditions, including drought condition, with high T/R (Top/Root) ratio, and it is considered that the water transport system of this plant is economical and could contribute to the accomplishment of higher productivity (Ito and Inanaga, 1988; Matsuda et al., 1991; Nada et al., 1994). Plants with high capacity to retain water even under drought conditions are generally superior in the following functions: water absorption of the roots (Trillana et al., 2001); osmotic adjustment (Inada et al., 1992), hydraulic conductance (Mencuccini and Comstock, 1999) and water storage capacity, partly compensating for transpiration with water in the plant

\footnotetext{
1 National Institute of Agrobiological Sciencies, Kannondai 2, Tsukuba, Ibaraki 305-8602, Japan

* Corresponding author (E-mail: nkiyoshi@nias.affrc.go.jp)
} 
(Itani et al., 1999; Stratton et al., 2000). . In the napiergrass plant, root weight is low (Matsuda et al., 1991) and the resistance to water flow is high in the shoot, particularly the nodal stem (Nagasuga et al., 1998; Nagasuga et al., 2002; Nagasuga, 2003). However, the decrease in leaf water status in the afternoon is low, regardless of high stomatal conductance during the daytime, which promotes leaf photosynthesis and transpiration. So these suggests that the regulation of water transport by the nodal stem could be useful for restricting excess water loss resulting from transpiration, besides other functions, such as water storage capacity, could also be alse associated with the maintenance of well water conditions in this plant.

In this study, two experiments were conducted for the elucidation of the water transport features of napiergrass plant. Firstly, daytime water transport regulation was examined from changes in the rates of photosynthesis $(P n)$ and transpiration $(T r)$ after the successive excisions of various plant positions. Secondly, changes in the transpiration parameters (plant transpiration rate, $P T r$; sap flow, which means water absorption rate by the root system, $S F$; leaf water potential, $\Psi_{\text {lear }}$; stomatal conductance, $G s$; water content per fresh weight, $F W C$ ) were examined for the understanding of the diurnal water balance in a plant. In the second experiment, particular emphasis was placed on the relationship between total PTr and WSC, which was suggested to be involved in the maintenance of water balance.

\section{MATERIALS AND METHOD}

\section{Materials}

Napiergrass, Pennisetum purpureum Schumach. var merkeron, was grown both in pots and in field conditions, in the experimental farm of the agricultural Faculty, Kyushu University, from 1997 to 2001.

\section{Growth conditions and experimental treatment \\ Field growth condition}

Shoots that sprouted from over-wintered stocks were transplanted and grown with a spacing of $50 \mathrm{~cm} \times 50 \mathrm{~cm}\left(4\right.$ hills $\left.\mathrm{m}^{-2}\right)$ in 1997 and $150 \mathrm{~cm} \times 50 \mathrm{~cm}\left(1.3 \mathrm{hills} \mathrm{m}^{-2}\right)$ in 1999 in a field of sandy soil. As the basic fertilization, $\mathrm{N}, \mathrm{P}_{2} \mathrm{O}_{5}$ and $\mathrm{K}_{2} \mathrm{O}$ were applied at 25, 10 and $10 \mathrm{~kg}$ per $10 \mathrm{a}$, respectively, and fowl compost was applied at $1000 \mathrm{~kg}$ per $10 \mathrm{a}$. These plants were used for the investigation of water transport regulation in 1997, and diurnal changes in transpiration parameter in 1999.

\section{Growth in pots}

Young shoots which had grown to the 7-8th leaf emergence stage were separated from the parent stocks, transplanted in $18 \mathrm{~L}$ pots filled with sandy soil, and grown during the summer of 2001. As the basic fertilization, $\mathrm{N}, \mathrm{P}_{2} \mathrm{O}_{5}$ and $\mathrm{K}_{2} \mathrm{O}$ were applied at 3,2 and $2 \mathrm{~g}$ per pot, respectively. At the time of transplanting, two thirds of each leaf's shoot was cut to prevent growth damage caused by water loss. These plants were used for the investigation of water storage capacity. 


\section{Investigation methods}

Plant excision diagnosis (PED)

The water transport situation of the napiergrass plant was evaluated by the responses of $P n$ and $T r$ directly after the excision of various positions of this plant in August 1997. The detail procedure was drawn in the previous studies (Nagasuga, 2003).

Transpiration parameters

In 1999, transpiration rate and $G s$ in the upper 5 leaves were measured with a steady-state porometer (LI-1600; LI-COR, USA). The Gs figures shown represent the average value of 5 leaves. $P \operatorname{Tr}$ was determined by multiplying the average transpiration rate of 5 leaves by the total leaf area. $\Psi_{\text {lear }}$ and $S F$ at a height of $5-10 \mathrm{~cm}$ in the stem, which meant water uptake rate of the root system, were measured with a thermocouple psychrometer (L-51, Wescor, USA) and a sap flow gage (SGB-19WS, Cambell USA), respectively. In 2001, PTr was directly measured by weighing the plant-cultivating pot with a digital scale (DI-10, Teraoka, Japan). The soil surface of each pot was covered by a vinyl film to prevent water evaporation from the soil. Fresh weight measurements were made in the morning (7:00, well water conditions), afternoon (15:00, the worst water conditions of a day), and 1 day after stopping the water supply. After that, total leaf area of a plant was measured with automatic area meter (AAA-M8, Hayashi-denkoh, Japan). $F W C$ and water storage capacity (WSC, compensatory water content in a plant for transpiration) were determined as follows:

$$
\begin{aligned}
& F W C=(F W-D W) / F W \\
& W S C=\left(F W_{\mathrm{am}}-F W^{*}\right) / \text { Daily } P T r
\end{aligned}
$$

where $F W$ and $D W$ represent fresh weight and dry matter weight of a plant, $F W_{\text {am }}$ was measured in the morning and $F W^{*}$ in the afternoon or on next day after stopping of the water supply. Daily PTr represents total $P T r$ in a day:

\section{RESULTS AND DISCUSSION}

The regulation of water transport in a plant can be understood according to changes in $P n$ and $T r$ after the excisions of various positions (Nagasuga et al., 1998; Nagasuga et al., 2002). $P n$ and $T r$ did not change after the successive excisions of lower positions of the transpiration stream in a plant (from the roots to the lower position of the nodal stem) but rapidly increased after the excision of the leaf sheath (located at the upper position of the nodal stem) in the morning (Fig. 1). However, the excision positions showing $P n$ and $T r$ increases were different between morning and afternoon. The changes in these parameters were detected by excising the stem base (located in the lower position of the transpiration stream) in the afternoon (Fig. 2). Water transport regulation by the nodal stem decreased under stress growth conditions and early growth stages, and then the stem base regulated water flow to the leaves instead (Nagasuga et al., 1998; Nagasuga et al., 2002). It was considered that the water transport regulation by the nodal stem decreased not only in the above conditions, but also in the afternoon, even in normal environmental conditions. Napiergrass plant does not have well water 


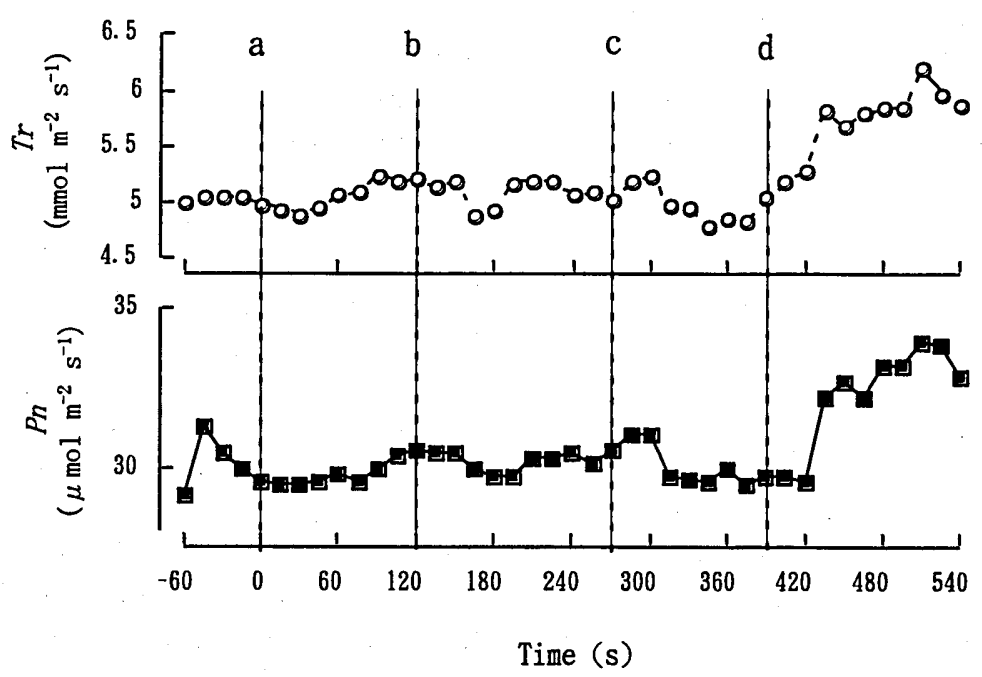

Fig. 1. Changes in transpiration rate and photosynthetic rate in napiergrass after plant excisions in the morning. Dotted lines of $a$, rhizome; $b$, stem base; $c$, lower position of the nodal stem to which measuremental leaf belong; $d$, leaf sheath were represented the time of plant excisions.

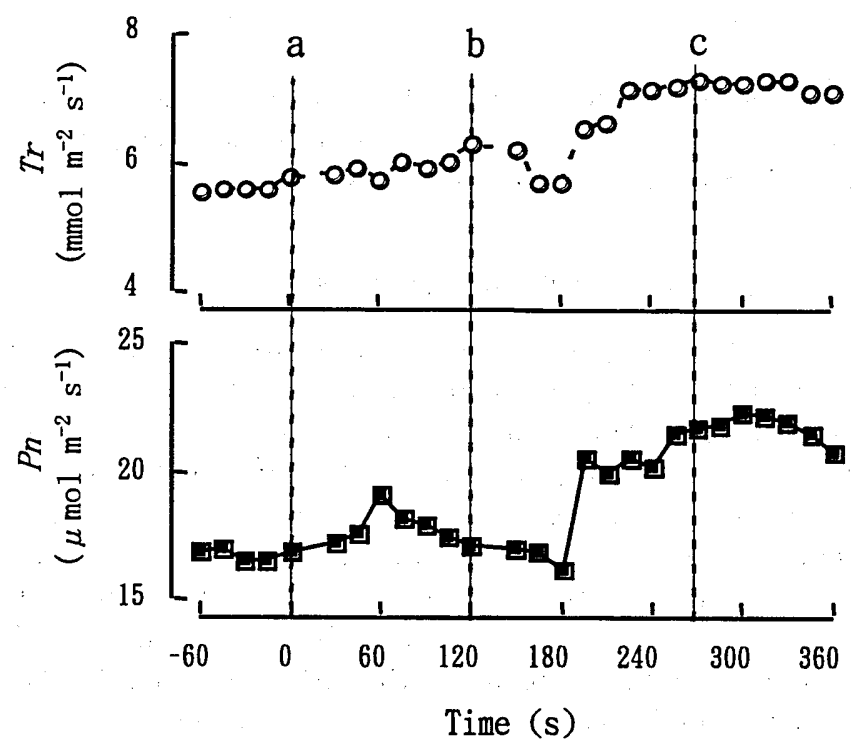

Fig. 2. Changes in transpiration rate and photosynthetic rate in napiergrass after plant excisions in the afternoon. Dotted lines of a, rhizome; $b$, stem base; $c$, lower position of the nodal stem to which measuremental leaf belong were represented the time of plant excisions. 
conditions in the afternoon because $P n$ is a little lower then, compared with the morning (Figs. 1 and 2), so the change in the main regulating position of water transport during the daytime could be associated with water conditions in a plant.

Water balance in a plant was understood from diurnal changes in transpiration parameters. Gs and PTr in mature napiergrass plants rapidly increased in the early morn-

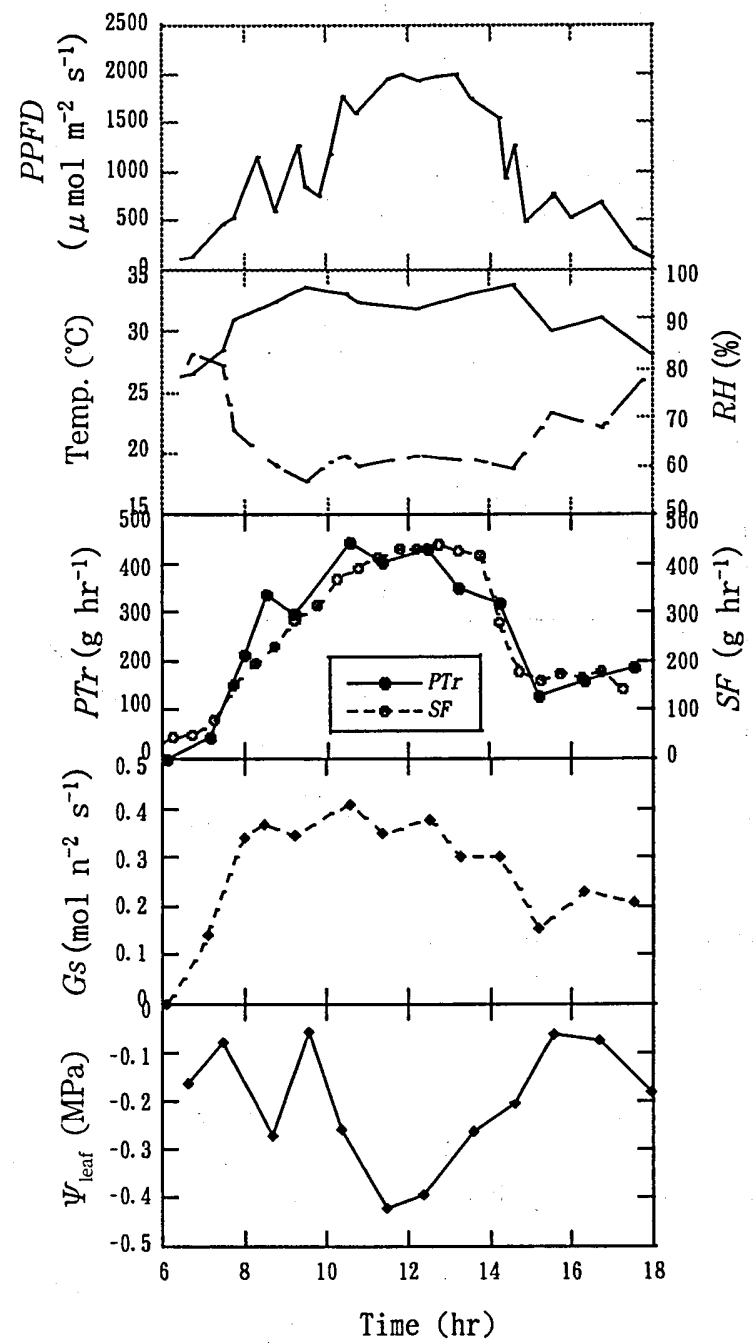

Fig. 3. Diurnal changes in climatic (A, B) and transpiration (C, D, E) parameters. PPFD, photosynthetic photon flux density; Temp., air temperature; $R H$, relative humidity; $P T r$, plant transpiration rate; $S F$, sap flow; $G s$, stomatal conductance, $\Psi_{\text {lear }}$ leaf water potential. 
ing, and maintained high values during the daytime. On the other hand, $S F$ increased slowly in the morning and became as high as PTr in the afternoon (Fig. 3). The difference of diurnal changes between PTr and $S F$ is often seen in trees that have high WSC (Goldstein et al:, 1998). WSC indicates partial utilization of stored water for the maintenance of the diurnal PTr and Gs. In the napiergrass plant, the change in PTr was a little different from that of $S F$, and $\Psi_{\text {leaf }}$ decreased until $S F$ reached higher value, in spite of high PTr (Figs. 3 and 4). This suggests that WSC of this plant should be higher and related to decrease in water condition in a plant during the daytime. It was estimated that $8 \%$ of the total PTr was compensated for by WSC from the difference between PTr and $S F$ in the daytime (Fig. 4, particularly the area of $P T r-S F$ over 0 ). Table 1 shows $F W, F W C$, water content reduction in a plant $(\triangle W C)$ and $\triangle W C$ per $F W(\triangle W C / F W)$ in the pot-cultivated young plants. Although water stress phenomena were not clearly identified in the leaves, the water content of the plants largely decreased in the afternoon

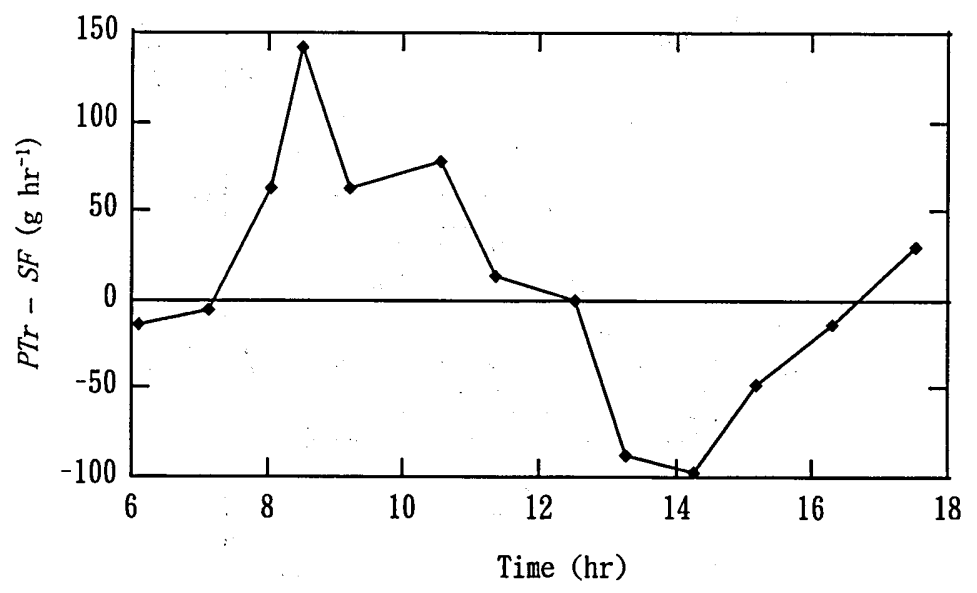

Fig. 4. Difference $(P T r-S F)$ between plant transpiration rate $(P T r)$ and sap flow $(S F)$ at the stem base. The area where $P T r-S F$ is over 0 represents contribution of water saved in the plant to $P T r$ instead of $S F$.

Table 1. Plant water content per fresh weight $(P W C)$, water content depression in a plant $(\triangle W C)$, $\triangle W C$ per fresh weight of a shoot $(\triangle W C / F W)$ and fresh weight of the shoot $(F W)$ in napiergrass plant.

\begin{tabular}{|c|c|c|c|c|c|c|c|}
\hline \multicolumn{3}{|c|}{$P W C(\%)$} & \multicolumn{2}{|c|}{$\Delta W C(\mathrm{~g})$} & \multicolumn{2}{|c|}{$W C / F W\left(\times 10^{-3} \mathrm{~g} \mathrm{~g}^{-1}\right)$} & \multirow[t]{2}{*}{$\overline{F W(\mathrm{~g})}$} \\
\hline Morning & Afternoon & Drought & Normal & Maximum & Normal & Maximum & \\
\hline 85.56 & 83.04 & 82.85 & 22.30 & 33.80 & 84.42 & 128.0 & 265.5 \\
\hline
\end{tabular}

The values in Morning, Afternoon and Drought were measured at morning (7:00), afternoon (15:00) and the next morning (9:00). Particularly, dry values were measured with the plants that showed leaf scrolling because of the stop of water supply in a day. Normal and maximum $\triangle W C$ represent the differences of water content of a plant between morning and afternoon or drought, respectively. 


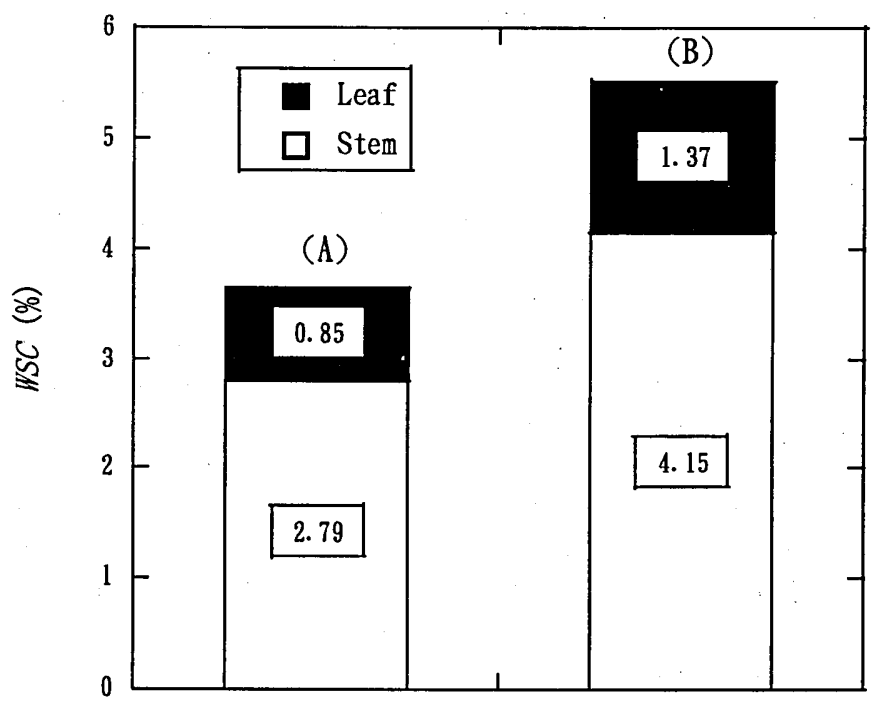

Fig. 5. Water storage capacity (WSC) in leaf and stem in napiergrass. WSC is shown as an indicator for the contribution of a plant water storage to total plant transpiration in the daytime (Daily $P T r$ ), and is calculated as $W S C=\Delta W C /$ Daily $P T r \times 100$.

$\triangle W C$, water content depression by transpiration during the daytime (A) and the stop of water supply to the plants (B).

(22.3 g). WSC was determined to be $3 \%$ directly from the relationship between daily PTr and $\triangle W C$, with particularly high $W S C$ in the stems (2 times higher than that of the leaves, Fig. 5A). Besides, when it was assumed that WSC functioned fully in leaf scrolling, maximum $W S C$ in leaf and stem were estimated to be $13.7 \%$ and $41.5 \%$, respectively (Fig. $5 B$ ). Since there were differences in growth conditions and estimation methods between two experiments, the estimated $W S C$ in the first experiment was a little different from that of the second experiment. However, both WSC values were high, so WSC of this plant could be relatively high among herbaceous plants.

Almost all water utilized for transpiration during the daytime is directly supplied by the roots in herbaceous plants, except in severe environmental conditions (Kitano and Eguchi, 1989). However, WSC of the napiergrass plants supplemented 3-8\% of daily transpiration even in normal environmental conditions, on the other hand, the change in $\Psi_{\text {leaf }}$ was almost the same as that of maize, which had a large root system and a low WSC ( $1 \%$, data not shown). Tree species with high $W S C$ can maintain high $\Psi_{\text {lear }}$ and gas exchange rates during the daytime (Goldstein et al., 1998) and dry season (Stratton et $a l ., 2000$ ). Similar to this, high $W S C$ in napiergrass plants could contribute to the maintenance of well water status, various physiological activities and high productivity under the high $\mathrm{T} / \mathrm{R}$ ratio.

In contrast to $G s$ and $P T r, S F$ increased slowly in the morning (Fig. 3). The regu- 
lation by the nodal stem and WSC mainly control water balance in low water supply situations (Figs. 1 and 3). On the other hand, although stronger demand for transpiration in the atmosphere deteriorated $P W C$ (by which the function of the nodal stem and WSC decreased in the afternoon), the regulation of water transport was strong in the stem base and then much water was supplied to the shoot by the roots (Figs. 2 and 3). As a result, transpiration maintenance of and active photosynthesis in the leaves and high productivity could be realized.

It was considered that WSC was associated with osmotic adjustment and water storage capacity in the parenchyma tissues (Inada et al., 1992; Itani et al., 1999). If osmotic adjustment largely contributed to $W S C$, osmotic potential would decrease along with the accumulation of osmotic adjustment materials (Inada et al., 1992). On the other hand, if the contribution of the latter factor was large, the development of parenchyma tissues would be seen in the stem and leaves (Itani et al., 1999). Actually, the parenchyma tissues of the stem were more developed than those of the leaves, so this factor was assumed to be associated with WSC. The discussion of whether high WSC results from accumulation of the osmotic adjustment materials, developed parenchyma tissues, or both will be addressed in future studies.

\section{REFERENCES}

Goldstein, G., J. L. Andrade, F. C. Meinzer, N. M. Holbrook, J. Cavelier, P. Jackson and A. Celis 1998 Stem water storage and diurnal patterns of water use in tropical forest canopy trees. Plant Cell and Environ., 21: 397-406

Inada, K., A. Matsuura and M. Yamane 1992 Interspecific differences in mechanism of drought tolerance among four cereal crops. J. Jpn. Crop Sci., 61: 87-95

Ishihara, K., T. Hirasawa, O. Iida and M. Kimura 1981 Diurnal course of transpiration rate, stomatal aperture, stomatal conductance, xylem water potential and leaf water potential in the rice plants under the different growth conditions. J. Jpn. Crop Sci., 50: 25-37

Itani, J., T. Oda and T. Numao 1999 Studies on mechanisms of dehydration postponement in cassava leaves under short-term soil water deficits. PPS, 2: 184-189

Ito, K. and S. Inanaga 1988 Studies on dry matter production of napiergrass. IV. Direct- and after-effects of temperature on leaf growth and dry matter production. J. Jpn. Crop Sci., 57: 699-707

Kitano, M. and H. Eguchi 1989 Quantitative analysis of transpiration stream dynamics in an intact cucumber stem by a heat flux control method. Plant Physiol., 89: 643-647

Matsuda, Y., F. Kubota, W. Agata and K. Ito 1991 Analytical study on high productivity in napier grass (Pennisetum purpureum Schumach.) 1. Comparison of the characteristics of dry matter production between napier grass and corn plants. J. Jpn. Grassl. Sci., 37: 150-156

Mencuccini, M. and J. Comstock 1999 Variability in hydraulic architecture and gas exchange of common bean (Phaseolus vulgaris) cultivars under well-watered conditions: interactions with leaf size. Aust. J. Plant Physiol., 26: 115-124

Nada, K., F. Kubota, W. Agata and F. Matsuda 1994 Characteristics of dry matter production and photosynthesis in napier grass and maize. Sci. Bull. Fac. Agr., Kyushu Univ., 48: 163-169

Nagasuga, K. 2003 Effect of growth light intensity condition on the water transport regulation and leaf photosynthesis in napiergrass (Pennisetum purpureum Schumach.). Bulletin of Institute of Tropical Agriculture, Kyushu Univ., 26: 53-58

Nagasuga, K., F. Kubota, K. Hirao and K. Nada 1998 A consideration of the water transport status in napier grass (Pennisetum purpureum Schumach.) based on the temporary rises in leaf photosynthesis and transpiration by plant excision. J. Jpn. Crop Sci., 67: 555-560

Nagasuga, K., F. Kubota and C. Nishiyama 2002 Specific Difference in water transport regulation in two high-Productive $\mathrm{C}_{4}$ crops, napiergrass, Pennisetum purpureum Schumach. and maize, Zea mays $\mathrm{L}$., 
grown in different light intensities. J. Fac. Agr., Kyushu Univ., 46: 267-274

Stratton, L., G. Goldstein and F. C. Meinzer 2000 Stem storage capacity of water transport: their functional significance in Hawaiian dry forest. Plant Cell and Environ., 23: 99-106

Trillana, N., T. Inamura, R. Chaudhary and T. Hone 2001 Comparison of Root System Development in Two Rice Cultivars During Stress Recovery from Drought and the Plant Traits for Drought Resistance PPS, 4: 155-159 